\title{
KJIM ${ }^{\top}$
}

\section{Sex difference in bowel preparation quality and colonoscopy time}

\author{
Young-Jae Hwang ${ }^{1,}$, Dong Woo Shin ${ }^{1,}$, Nayoung Kim ${ }^{1,2}$, Hyuk Yoon ${ }^{1}$, Cheol Min Shin ${ }^{1}$, Young Soo Park ${ }^{1}$, \\ and Dong Ho Lee ${ }^{1,2}$
}

\begin{abstract}
${ }^{1}$ Department of Internal Medicine, Seoul National University Bundang Hospital, Seongnam; ${ }^{2}$ Department of Internal Medicine and Institute of Liver Research, Seoul National University College of Medicine, Seoul, Korea
\end{abstract}

\section{Received: May 21, 2019 \\ Revised : July 1, 2019 \\ Accepted: July 5, 2019 \\ Correspondence to \\ Nayoung Kim, M.D. \\ Department of Internal \\ Medicine, Seoul National \\ University Bundang Hospital, 82 Gumi-ro 173beon-gil, Bundang- gu, Seongnam 13620, Korea \\ Tel: + 82-31-787-7008 \\ Fax: + 82-31-787-4051 \\ E-mail: nayoungkim49@empas.com https://orcid.org/0000-0002- 9397-0406}

*These authors contributed equally to this work.
Background/Aims: The length of colon is known to be longer in females than in males. In addition, the morphology of colon cancer is different between males and females. The aim of this study was to investigate sex differences in Boston bowel preparation score (BBPS) and colonoscopy insertion time.

Methods: This study retrospectively analyzed medical records and colonoscopy readings of subjects who underwent colonoscopy at Seoul National University Bundang Hospital from March 2015 to April 2018. BPPS was used to evaluate the degree of colon cleanness before colonoscopy. Statistical analysis was performed to compare demographic, clinical, and outcome variables between two groups.

Results: The study group consisted of a total of 12,561 patients $(6,148$ females and 6,413 males). Mean age was $57.8 \pm 13.5$ years for females and $57.5 \pm 13.8$ years for males $(p=0.695)$. Females showed better bowel preparation than males (mean total score: $7.4 \pm 1.8$ vs. $7.2 \pm 1.9, p=0.001$; total score $\geq 6: 5,340$ [86.9\%] vs. 5,437 [84.8\%], $p=0.001 ;$ BBPS $\geq 2$ for all segments: $5,048[82.1 \%]$ vs. 5,097 [79.5\%], $p<0.001$ ). However, cecal intubation time $(8.3 \pm 6.2$ minutes vs. $6.2 \pm 6.1$ minutes, $p<0.001)$ and withdrawal time $(7.9 \pm 3.5$ minutes vs. $7.4 \pm 3.1$ minutes, $p<0.001)$ were longer in males.

Conclusions: There were sex differences in BBPS, cecal intubation time, and withdrawal time for subjects undergoing colonoscopy.

Keywords: Colonoscopy; Colorectal cancer; Gender; Sex; Preparation

\section{INTRODUCTION}

Incidence of colorectal cancer (CRC) has increased in the world ( 8.2 per 100,000 in year 2008 vs. 17.2 per 100,000 in year 2012) [1,2]. Interestingly, there is sex difference of CRC in terms of incidence (10.0 per 100,000 in males vs. 9.2 per 100,000 in females) and mortality (8.0 per 100,000 in males vs. 9.0 per 100,000 in females). In Korea, the incidence of CRC has rapidly increased; CRC became the second most common cancer (52.6 per $100,000)$. CRC was the sixth most common cancer $(16.3$ per 100,000) among cancers that caused mortality [3].
Similar to other countries, there is also sex difference of CRC in term of incidence (62.5 per 100,000 in males vs. 42.7 per 100,000 in females) and mortality (18.5 per 100,000 in males vs. 14.1 per 100,000 in females) in Korea $[4,5]$. Male is a risk factor of CRC. CRC also develops earlier in males than in females. Thus the screening protocol of CRC should be different between males and females $[4,5]$. However, CRC screening guidelines do not distinguish males and females. CRC developed from proximal (right-sided) or distal (left-sided) colon shows differences in incidence according to geographic region, age and sex $[6,7]$. It is known that patients with proximal 
colon cancer are older and having more females than those with distal colon cancer. In addition, there is a difference in cancer morphology. That is, proximal colon cancer is more often flat while distal colon cancer has a polypoid-type which can be more easily detected by colonoscopy [8]. Tumor location and prognosis of CRC are also different between males and females. However, studies that consider sex specific design and interpretation of CRC are insufficient.

Colonoscopy is important for screening and diagnosis of CRC [5]. As inadequate bowel preparation affects the effectiveness and accuracy of colonoscopy examination. Thus, bowel preparation and colonoscopy quality management are important $[9,10]$. Several studies have reported that age, sex, physical activity, and disease are associated with bowel preparation [11-13]. The length of colon is known to be longer in females than in males $[14,15]$. However, there has been no research on each factor so far. In addition, previous studies have not identified other colonoscopy quality factors including cecal intubation rate, insertion time, and polyp detection rate together [11-13]. We hypothesize that there are sex differences in colonoscopy preparation quality, cecal intubation time, and withdrawal time (from point of cecal intubation to final withdrawal). If there is difference in colonoscopy quality between sexes, CRC screening guidelines which do not distinguish females from males should be revised to improve the high mortality and poor prognosis of female CRC patients [1-4]. With this background, the aim of this study was to determine sex difference of colonoscopy quality in terms of bowel preparation, insertion time, withdrawal time, and polyp detection rate.

\section{METHODS}

\section{Data source}

Medical records and colonoscopy readings of subjects who underwent colonoscopy at Seoul National University Bundang Hospital (SNUBH) from March 2015 to April 2018 were analyzed.

Informed consent was waived by Institutional Review Board of SNUBH (No. B-1812/513-106). Subjects were searched using SNUBH's Clinical Data Warehouse, the hospital's own database analysis program [16]. In addi- tion, medical information was collected from electronic medical record system, including sex, age, past medical history, indication of colonoscopy, sedation medication, name of colonoscopist, colonoscopy finding, Boston bowel preparation score (BBPS), number of polyp, number of diverticulum, cecal intubation time and withdrawal time. We excluded colonoscopy cases with history of surgery on colon or abdomen. In addition, colonoscopy cases done by colonoscopists within 5 years were excluded.

\section{Analysis of colonoscopy quality indicators}

We examined sex difference of baseline characteristics including age, history of surgery, indications of colonoscopy, sedation medication and bowel preparation drug. We also identified sex difference of colonoscopy quality indicators including BBPS, cecal intubation rate, cecal intubation time, withdrawal time and polyp detection rate $[9,10]$.

There are various bowel preparation scales including Aronchick bowel preparation scale (ABPS) [17-20], Ottawa bowel preparation scale (OBPS) [18-20], and BBPS [19-21]. The ABPS was widely used to assess bowel preparation quality ranging from excellent (1 point) to inadequate ( 5 points) by evaluating the percentage of total colonic mucosal surface covered by fluid or stool without scoring separate colon segments [19]. The OBPS can access colonic mucosal cleanliness by colon segment on a scale of o (excellent) to 4 (inadequate). The BBPS was developed in 2009. It has been validated in various studies [19-21]. The BBPS separates the colon into three segments: right, transverse, and left colon. Each segment is scored from o to 3 , with a score of 3 indicating good bowel cleansing. Total score for the three segments ranges from o to 9. We chose the BBPS to assess bowel preparation. The BBPS is a useful scale because it is associated with polyp detection rate and follow-up interval of colonoscopy [21,22]. BBPS score higher than 6 was defined as adequate bowel preparation. A recent study has defined adequate preparation as having BBPS score of 2 or 3 for all colon segments [23]. If a subject had a BBPS score of o or 1 in any colon segment, the preparation was considered inadequate.

Difference of BBPS was analyzed according to two kinds of bowel preparation drugs, Coolprep (Taejoon Pharmaceutical, Seoul, Korea) and Picosolution (Pharm- 
bio Korea, Seoul, Korea). Coolprep consists of two pouches (A and B). Components of pouch A contain polyethylene glycol $50 \mathrm{~g}$, potassium chloride $0.5075 \mathrm{~g}$, sodium chloride $1.3455 \mathrm{~g}$ and sodium sulfate anhydrous 3.75 g. Components of pouch B contain ascorbic acid 2.35 $\mathrm{g}$ and sodium ascorbate $2.95 \mathrm{~g}$. This should be diluted in $2 \mathrm{~L}$ before intake. Components of Picosolution in 170 $\mathrm{mL}$ contain citric acid $12 \mathrm{~g}$, magnesium oxide $3.5 \mathrm{~g}$ and sodium picosulfate hydrate $10 \mathrm{mg}$. After drinking each bottle of Picosolution in $170 \mathrm{~mL}$ subjects should drink 1 $\mathrm{L}$ water according to the regimen. However, when subjects had history of constipation three bottles of Picosolution $(510 \mathrm{~mL})$ were recommended.

\section{Statistical analyses}

Continuous variables are expressed as mean $\pm \mathrm{SD}$ (range). Categorical variables are presented as absolute values and percentages. All quantitative variables were compared between the two groups using an indepen- dent samples $t$ test to evaluated sex difference of colonoscopy quality indicators. Fisher's exact test was used for categorical variables as appropriate. All statistical tests were two-sided without adjustment for multiple comparisons. Statistical significance was considered when $p$ value was less than 0.05 . All analyses were carried out using SPSS for Windows version 22.0 (IBM Co., Armonk, NY, USA).

\section{RESULTS}

\section{Subject characteristics}

Data from 12,561 colonoscopies were analyzed. These colonoscopies were done by 11 colonoscopists who were professors in gastroenterology with colonoscopy experience of 5 years or more. Colonoscopies were performed for 6,413 males and 6,148 females. Characteristics of these 12,561 cases are shown in Table 1. Age was similar

Table 1. Baseline characteristics of the study population

\begin{tabular}{|c|c|c|c|}
\hline Variable & Male $(\mathrm{n}=6,413)$ & Female $(n=6,148)$ & $p$ value $^{a}$ \\
\hline Age, yr & $57.5 \pm 13.8$ & $57.8 \pm 13.5$ & 0.695 \\
\hline $20-39$ & $754(11.6)$ & $584(9 \cdot 5)$ & \\
\hline $40-59$ & $2,615(40.8)$ & $2,545(41.4)$ & \\
\hline $60-75$ & $2,505(39.1)$ & $2,527(41.1)$ & \\
\hline$>75$ & $548(8.5)$ & $492(8.0)$ & \\
\hline \multicolumn{4}{|l|}{ Indications of colonoscopy } \\
\hline Screening & $2,599(40.5)$ & $2,535(41.2)$ & 0.425 \\
\hline Symptoms & $1,089(17.0)$ & $1,420(23.1)$ & $<0.001$ \\
\hline Colorectal cancer & $406(6.3)$ & $289(4.7)$ & $<0.001$ \\
\hline Polyp & $1,156(18.0)$ & $666(10.8)$ & $<0.001$ \\
\hline Inflammatory bowel disease & $371(5.8)$ & $214(3 \cdot 5)$ & $<0.001$ \\
\hline Others & $792(12.3)$ & $1,024(16.7)$ & \\
\hline Non-sedation colonoscopy & $68(1.0)$ & $54(0.8)$ & 0.503 \\
\hline Sedation colonoscopy & $6,345(98.9)$ & $6,094(99.2)$ & \\
\hline Midazolam, mg & $4 \cdot 5 \pm 1.0$ & $4.3 \pm 1.2$ & $<0.001$ \\
\hline Pethidine, mg & $36.7 \pm 12.8$ & $38.2 \pm 12.9$ & 0.001 \\
\hline Bowel preparation drug ${ }^{b}$ & & & $<0.001$ \\
\hline Coolprep & $6,248(97.6)$ & $5,912(96.3)$ & \\
\hline Picosolution & $156(2.4)$ & $225(3.7)$ & \\
\hline
\end{tabular}

Values are presented as mean \pm SD or number (\%).

${ }^{a} p<0.05$ was statistically significant.

${ }^{b}$ Missing value: preparation drug. Twenty cases (nine males, 11 females) could not be identified in the Clinical Data Warehouse. Maybe these subjects received prescription of preparation drug from other doctors. 
between male and female groups ( $57.5 \pm 13.8$ years vs. 57.8 \pm 13.5 years, $p=0.695)$. The ratio of screening colonoscopy was similar between males and females $(p=0.425)$. The ratio of colonoscopy due to symptom (abdominal pain, hematochezia, and diarrhea) was higher $(p<0.001)$ in fe- males. On the contrary, the ratio of colonoscopy due to CRC, polyp, and inflammatory bowel disease (IBD) was higher in males $(p<0.001$, respectively) [3]. The dose of midazolam for sedation was higher in males $(4.5 \pm 1.0 \mathrm{mg}$ vs. $4.3 \pm 1.2 \mathrm{mg}, p<0.001)$. However, the dose of pethidine

Table 2. Sex differences in bowel preparation score and colonoscopy insertion time

\begin{tabular}{|c|c|c|c|}
\hline Variable & Male $(n=6,413)$ & Female $(n=6,148)$ & $p$ value $^{a}$ \\
\hline BBPS, total score & $7.2 \pm 1.9$ & $7.4 \pm 1.8$ & 0.001 \\
\hline Right colon & $2.2 \pm 0.8$ & $2.3 \pm 0.8$ & \\
\hline Transverse colon & $2.5 \pm 0.7$ & $2.6 \pm 0.6$ & \\
\hline Left colon & $2.4 \pm 0.7$ & $2.5 \pm 0.6$ & \\
\hline BBPS, total $\geq 6$ & $5,437(84.8)$ & $5,340(86.9)$ & 0.001 \\
\hline Achievement of adequacy ${ }^{b}$ & $5,097(79 \cdot 5)$ & $5,048(82.1)$ & $<0.001$ \\
\hline Preparation result (BPPS) & & & $<0.001$ \\
\hline Inadequate $(0-3)$ & $337(5 \cdot 3)$ & $258(4.2)$ & $<0.001$ \\
\hline Poor $(4-5)$ & $639(10.0)$ & $550(8.9)$ & \\
\hline Good (6-7) & $2,151(33 \cdot 5)$ & $1,834(29.8)$ & \\
\hline Excellent (8-9) & $3,286(51.2)$ & $3,506(57 \cdot 0)$ & $<0.001$ \\
\hline Cecal intubation rate & $6,104(95.2)$ & $5,867(95.4)$ & 0.512 \\
\hline Cecal intubation time, min & $6.2 \pm 6.1$ & $8.3 \pm 6.4$ & $<0.001$ \\
\hline Withdrawal time, min & $7 \cdot 9 \pm 3 \cdot 5$ & $7 \cdot 4 \pm 3.1$ & $<0.001$ \\
\hline
\end{tabular}

Values are presented as mean \pm SD or number (\%).

BBPS, Boston bowel preparation score.

${ }^{a} p<0.05$ was statistically significant.

${ }^{\mathrm{b}}$ Patients with BBPS scores of 2 or 3 for all colon segments.
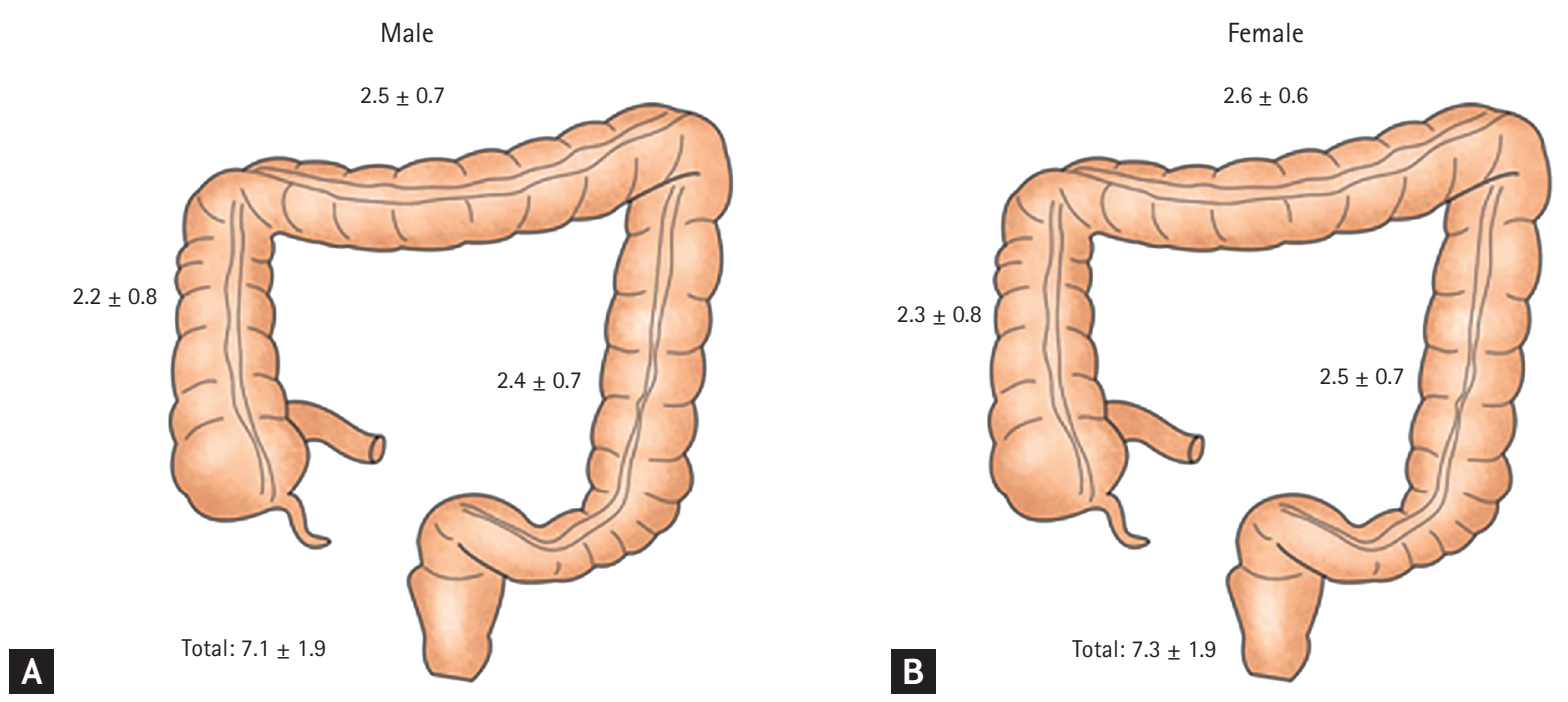

Figure 1. Comparison of Boston bowel preparation scale between (A) male and (B) female depending on colon segment (ascending, transverse, and descending colon). Total Boston bowel preparation scale was significantly higher in female than male $(p=0.001)$. However, there was no significant difference in each segmental score. 
Table 3. Sex differences in polyp detection rate

\begin{tabular}{|c|c|c|c|}
\hline Variable & Male $(\mathrm{n}=6,413)$ & Female $(n=6,148)$ & $p$ value $^{\mathrm{a}}$ \\
\hline Biopsy done & $2,921(45 \cdot 5)$ & $1,943(31.6)$ & $<0.001$ \\
\hline Polyp detection rate & $2,060(32.1)$ & $1,277(20.8)$ & $<0.001$ \\
\hline 1-2 Polyps & $1,696(26.4)$ & $1,123(18.3)$ & $<0.001$ \\
\hline 3-6 Polyps & $326(5.1)$ & $136(2.2)$ & $<0.001$ \\
\hline$\geq 7$ Polyps & $38(0.6)$ & $18(0.3)$ & $<0.001$ \\
\hline Diverticulum & $610(9.5)$ & $378(6.1)$ & $<0.001$ \\
\hline 1-2 Diverticulum & $234(3.6)$ & $192(3.1)$ & 0.052 \\
\hline$\geq 3$ Diverticulum & $376(5.9)$ & $186(3.0)$ & $<0.001$ \\
\hline
\end{tabular}

Values are presented as number (\%).

${ }^{a} p<0.05$ was statistically significant.

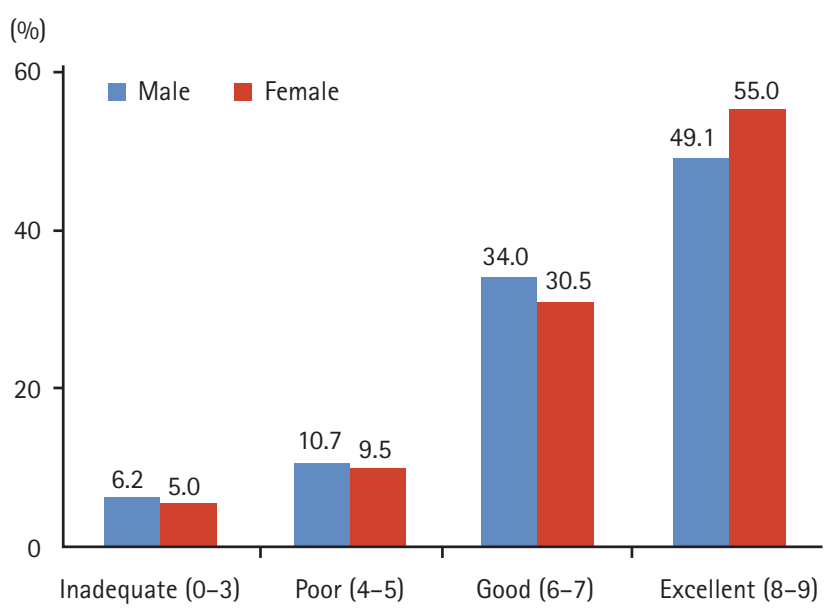

Figure 2. Comparisons of bowel preparation ratings between male and female.

was lower in males $(36.7 \pm 12.8 \mathrm{mg}$ vs. $38.2 \pm 12.9 \mathrm{mg}, \mathrm{p}$ $=0.001$ ). Picosolution was more frequently selected for bowel preparation solution in females $(p<0.001)$.

\section{Sex difference of colonoscopy quality indicators}

Total BBPS indicating the degree of colon cleanness was lower in males (7.2 \pm 1.9 vs. $7.4 \pm 1.8, p=0.001)$. Each segment was slightly higher in females than in males (Table 2, Fig. 1). The proportion of patients with an adequate bowel preparation (BBPS $\geq 6$ ) was significantly lower in males than female group $(5,437$ [84.8\%] in males vs. 5,340 [86.9\%] in females, $p=0.001$ ). The proportion of patients with an adequate bowel preparation (BBPS $\geq$ 2 for all segments) was also significantly lower in males than in females $(5,097$ [79.5\%] in males vs. 5,048 [82.1\%] in females, $p<0.001$ ). In addition, we classified patients by preparation result of BBPS (inadequate, o to 3; poor, 4 to 5; good, 6 to 7; excellent, 8 to 9) (Fig. 2). The ratio of patients with excellent preparation result (BBPS 8 to 9) was significantly $(p<0.001)$ higher in females than in males (Table 2). The ratio of patients with inadequate preparation result (BBPS o to 3 ) was significantly $(p<0.001)$ higher in males.

There was no significant difference in cecal intubation rate between males and females (95.2\% in males vs. 95.4\% in females, $p=0.512$ ) (Table 2). However, cecal intubation time was significantly longer in females (male, $6.2 \pm 6.1$ minutes vs. female, $8.3 \pm 6.4$ minutes, $p<0.001$ ) In addition, withdrawal time was significantly longer in males $(7.9 \pm 3.5$ minutes in males vs. $7.4 \pm 3.1$ minutes in females, $p<0.001)$.

Colonoscopy biopsy was more frequently performed in males $(p<0.001)$. Polyp detection rate was also higher in males (32.1\% vs. $20.8 \%, p<0.001$ ) (Table 3$)$. In addition, the number of cases with three or more polyps was higher in males $(p<0.001)$. Diverticulum was also more frequently detected in males (9.5\% vs. $6.1 \%, p<0.001)$.

\section{Sex difference of bowel preparation score according to drug}

We also analyzed sex difference of BBPS according to bowel preparation drug (Table 4). Coolprep was the most commonly used bowel preparation drug $(n=12,160)$. Picosolution was used in 381 patients. Total BBPS score of Coolprep was significantly lower in females $(7.2 \pm 1.9$ in 
Table 4. Difference of BBPS according to bowel preparation drugs

\begin{tabular}{|c|c|c|c|}
\hline Variable & Male $(\mathrm{n}=6,404)^{\mathrm{a}}$ & Female $(\mathrm{n}=6,137)^{\mathrm{a}}$ & $p$ value $^{\mathrm{b}}$ \\
\hline \multicolumn{4}{|l|}{ BBPS, total score } \\
\hline Coolprep $(n=12,160)$ & $7.2 \pm 1.9$ & $7 \cdot 4 \pm 1.8$ & 0.026 \\
\hline Picosolution $(n=381)$ & $7.6 \pm 1.7$ & $7.6 \pm 1.7$ & 0.927 \\
\hline \multicolumn{4}{|l|}{ BBPS, total $\geq 6$} \\
\hline Coolprep & & & 0.001 \\
\hline BBPS, total $\geq 6$ & $5,288(84.6)$ & $5,125(86.7)$ & \\
\hline BBPS, total $<6$ & $960(15 \cdot 4)$ & $787(13 \cdot 3)$ & \\
\hline Picosolution & & & 0.926 \\
\hline BBPS, total $\geq 6$ & $141(90.4)$ & $204(90.7)$ & \\
\hline BBPS, total $<6$ & $15(9.6)$ & $21(9 \cdot 3)$ & \\
\hline \multicolumn{4}{|l|}{ Achievement of adequacy ${ }^{c}$} \\
\hline Coolprep & & & $<0.001$ \\
\hline Adequate & $4,956(79 \cdot 3)$ & $4,841(81.9)$ & \\
\hline Inadequate & $1,292(20.7)$ & $1,071(18.1)$ & \\
\hline Picosolution & & & 0.732 \\
\hline Adequate & $134(85 \cdot 9)$ & $196(87.1)$ & \\
\hline Inadequate & $22(14.1)$ & $29(12.9)$ & \\
\hline
\end{tabular}

Values are presented as mean \pm SD or number (\%).

BBPS, Boston bowel preparation score.

${ }^{a}$ Missing value: preparation drug. Twenty cases (nine males, 11 females) for preparation drugs could not be identified in the clinical data warehouse. Maybe these subjects received prescription of preparation drug from other doctors.

${ }^{\mathrm{b}} \mathrm{p}<0.05$ was statistically significant.

${ }^{\mathrm{c}}$ Patients with BBPS scores of 2 or 3 for all colon segments.

males vs. 7.4 \pm 1.8 in females, $p=0.026$ ). Adequate bowel preparation (BBPS $\geq 6$ ) of Coolprep was also lower in males $(5,288$ [84.6\%] in males vs. 5,125 [86.7\%] in females, $p=0.001)$. In recent guideline of adequate bowel preparation (BBPS $\geq 2$ for all segments), the ratio of adequate bowel preparation with Coolprep was lower in males $(4,956$ [79.3\%] in males vs. 4,841 [81.9\%] in females, $p<$ $0.001)$. However, there was no sex difference in the ratio of bowel preparation with Picosolution.

Next, we analyzed sex difference of BBPS according to history of polypectomy and IBD (Table 5). Regarding history of polypectomy, total BBPS $(7.4 \pm 1.8$ in males vs. $7.7 \pm 1.6$ in females, $p<0.001)$, adequate bowel preparation $(\mathrm{BBPS} \geq 6)(958$ [88.3\%] in males vs. 572 (91.7\%) in females, $p=0.028$ ), and achievement of adequacy (911 [84.0\%] in males vs. 550 [88.1\%] in females, $p=0.018)$ were significantly lower in males.

For cases with IBD, adequate bowel preparation was significantly higher in males (359 [96.8\%] in males vs. 196 [91.6\%] in females, $p=0.011$ ).

\section{DISCUSSION}

Recently, there has been a growing interest in sex specific difference. Some studies have reported health difference between males and females [14,15,24]. Sex and gender differences show diverse physiological and psychological factors. Sex hormones and gender differences might play important roles in disease development and progression [24]. For instance, Menon et al. [25] have suggested that sex hormones can directly affect bacterial metabolism, bacterial growth, and gene expression of virulence factors through steroid nuclear receptor expression including estrogen receptor $\beta$. In addition, Kim et al. [26] have demonstrated that reflux symptoms affect 
Table 5. Difference of BBPS according to history of polypectomy $(n=1,709)$ and inflammatory bowel disease $(n=585)$

\begin{tabular}{lccc}
\hline Variable & Male & Female & $p^{\text {value }}$ \\
\hline History of polypectomy & 1,085 & 624 & \\
\hline BBPS, total score & $7.4 \pm 1.8$ & $7.7 \pm 1.6$ & $<0.001$ \\
\hline BPPS, total $\geq 6$ & $958(88.3)$ & $572(91.7)$ & 0.028 \\
\hline Achievement of adequacy $^{\mathrm{b}}$ & $911(84.0)$ & $550(88.1)$ & 0.018 \\
Inflammatory bowel disease $^{\mathrm{a}}$ & 371 & 214 & 0.058 \\
\hline BBPS, total score & $7.9 \pm 1.4$ & $7.8 \pm 1.7$ & 0.011 \\
\hline BPPS, total $\geq 6$ & $359(96.8)$ & $196(91.6)$ & 0.137 \\
\hline Achievement of adequacya & $350(94.3)$ & $195(91.1)$ & \\
\hline
\end{tabular}

Values are presented as mean $\pm \mathrm{SD}$ or number (\%).

BBPS, Boston bowel preparation score.

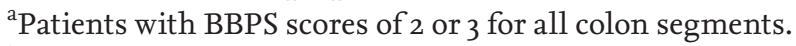

${ }^{\mathrm{b}} \mathrm{p}<0.05$ was statistically significant.

female patients with gastroesophageal reflux disease more than in male ones, and quality of life was also more impaired in females. In terms of cancer, Kotake et al. [27] have shown that reduced risk of cancer-specific death for women relative to men persists over time. Zheng et al. [28] have shown that sex hormones play a crucial role in the pathogenesis and development of hepatitis B virus-induced hepatocellular carcinoma. Males with private insurance undertook colonoscopy more frequently [29]. However, employed males were less likely to eat salty food, be older, and smoke [29]. Diagnostic interval was longer for females than for males in CRC (mean difference; 10.4 days; $95 \%$ confidence interval, 4.3 to 16.5 ; $p$ $=0.001)$ [30].

There have been some reports regarding sex difference in colonoscopy quality [13,31-33]. Ness et al. [13] have suggested that male sex (odds ratio, 0.85 ) is associated with inadequate bowel preparation. Similarly, Rotondano et al. [31] have examined factors associated with quality of bowel cleansing and found that men gender is a predictor of inadequate cleansing at right colon and left colon ( $p=0.040$ and $p=0.014$, respectively). In addition, Akere and Otegbayo [32] have examined 167 patients to find factors affecting cecal intubation time. They found that men are associated with prolonged cecal intubation time $(913.86 \pm 453.28$ seconds in males vs. $910.44 \pm 513.33$ seconds in females, $p=0.443)$. In contrast, males showed higher success rate of cecal intubation within $20 \mathrm{~min}$ utes than females $(83.9 \%$ in males vs. $77.6 \%$ in females, $p=0.004$ ) [33]. However, there is a lack of research that conclusively proves the sex difference in colonoscopy quality. In addition, previous studies have limitation such as small sample size [31] and insufficient variables $[31,32]$. In addition, there has been no research analyzing colonoscopy quality between males and females like the present study. Furthermore they only statistically analyzed sex as one factor for multivariance [13,31-33]. There are various colonoscopy quality indicators including colonoscopy surveillance, cecal intubation rate, adenoma detection rate ( $\geq 25 \%$ in males and $\geq 15 \%$ in females), colonoscopy withdrawal time (average $\geq 6$ minutes) and quality of colon preparation [34]. However, few studies have been performed with a comprehensive approach in terms of sex specific manners.

In the present study, we investigated sex difference in colonoscopy quality in many aspects using a big administrative database. Colonoscopy quality indicators including adenoma detection rate, colonoscopy withdrawal time, and quality of colon preparation are important to detect colon polyp and CRC in early stages [34]. However, there has been no study about sex difference in these indicators. Males and females have different incidence and mortality of CRC. Our results suggest that sex difference of colonoscopy quality indicator might be associated with early detection and mortality of CRC.

Clearly, sex difference was identified in bowel preparation. We analyzed various guidelines for adequate bowel preparation and found that females showed bet- 
ter bowel preparation results. It is known that bowel preparation is influenced by various factors [11-13,35,36]. Our study showed that sex factor could influence bowel preparation based on a large cohort database. Our results suggest that we should more carefully educate male patients who receive colonoscopy for adequate bowel preparation. Whether sex difference of bowel preparation is associated with chromosome or genetic difference merits further study.

Our study showed sex difference in cecal intubation time and withdrawal time. Sex difference of cecal intubation time might be associated with anatomical difference between males and females [14,15]. Thus, we need to schedule female patients with enough colonoscopy time. Sex difference of withdrawal time might be associated with polyp detection rate. Male showed higher polyp detection rate. Therefore, withdrawal time in males might need to be longer than in females.

Our study showed that polyp detection rate was different between males and females. It might be associated with the higher incidence of CRC in males [1-3]. Thus, careful colonoscopy inspection is needed for males. These results suggest that different indication of colonoscopy and colonoscopy follow-up interval might be needed based on sex difference of bowel preparation method and colonoscopy withdrawal time. More studies are needed to determine the appropriate colonoscopy follow-up term for males.

We analyzed sex difference of bowel preparation with bowel preparation drugs Coolprep and Picosolution widely used in Korea. Some studies have reported that these two drugs have no significant adverse effects with similar bowel of cleansing [37-40]. In the present study, females showed better total BBPS score, adequate bowel preparation (BBPS $\geq 6$ ), and recent adequate bowel preparation (BBPS $\geq 2$ for all segments) in Coolprep. However, there was no sex difference in cases of Picosolution in contrast to Coolprep. We cautiously believe that the reason might be because subjectsneedes to drink $2 \mathrm{~L}$ of Coolprep with mixed solution from the beginning. Thus, males might not have followed the instruction more precisely than females. Our results suggest that bowel preparation might be different depending on which bowel preparation drugs are taken. Thus, male patients should be educated how to clean bowel more carefully. In addition, it is necessary to study how to clean the bowel in males. Whether different bowel preparation drugs show different effectiveness remains controversial. Previous reports have suggested that bowel preparation is associated with not only drugs, but also drug compliance and fiber diet education [35,36]. Our study showed that there was a sex difference in bowel preparation status using bowel preparation drugs. Thus, when Coolprep or Picosolution was planned, this result should be carefully considered. In addition, there was a difference in size between Coolprep and Picosolution groups. Therefore, more studies are needed.

We thought that analysis of colonoscopy by experienced colonoscopists was our study's strength. The skill and career of colonoscopist depending on training period can affect cecal intubation time and polyp detection rate. Our study eliminated the selection bias due to exclusion of colonoscopy cases by colonoscopists with experience of less than 5 years.

However, our study has some limitations. First, this study was performed in one institute due to the Personal Information Protection Acting Korea. However, there was an advantage of research because description format was made before this study. Thus a consistent approach was possible and description was well educated with the figure to avoid selection bias. Second, we analyzed colonoscopy information according to electronic medical records for a large number of cases. However, we could not verify other factors such as patient's compliance and history of colonoscopy. In addition, our study could not deal with analysis of pathologic result. We thought that analysis of pathologic findings including grade of adenoma and carcinoma should be needed.

In conclusion, there was a sex difference in colonoscopy indicator. Males showed less clean bowel preparation. However, polyp detection rate in males was higher than that in females. Thus, males should be educated regarding how to perform bowel preparation carefully. Colonoscopists need to reserve relatively more time of colonoscopy for females. Whether the sex difference of various colonoscopy indicators is associated with chromosome or genetic difference merits further study.

\section{KEY MESSAGE}

1. We identified sex difference in bowel preparation, cecal intubation time, withdrawal time, 
and polyp detection rate. Males had poorer bowel preparation and higher polyp detection rate than females.

2. Males need education regarding how to perform bowel preparation carefully. Females need plenty of time for colonoscopy insertion. Males need plenty of withdrawal time.

\section{Conflict of interest}

No potential conflict of interest relevant to this article was reported.

\section{Acknowledgments}

This research was supported by Support Program for Women in Science, Engineering and Technology through the Center for Women In Science, Engineering and Technology (WISET) funded by the Ministry of Science and ICT (No. WISET202003GIo1).

\section{REFERENCES}

1. Ferlay J, Shin HR, Bray F, Forman D, Mathers C, Parkin DM. Estimates of worldwide burden of cancer in 2008: GLOBOCAN 2008. Int J Cancer 2010;127:2893-2917.

2. Ferlay J, Soerjomataram I, Dikshit R, et al. Cancer incidence and mortality worldwide: sources, methods and major patterns in GLOBOCAN 2012. Int J Cancer 2015;136:Е359-E386.

3. Jung KW, Won YJ, Kong HJ, Lee ES; Community of Population-Based Regional Cancer Registries. Cancer statistics in Korea: incidence, mortality, survival, and prevalence in 2015. Cancer Res Treat 2018;50:303-316.

4. Kim SE, Paik HY, Yoon H, Lee JE, Kim N, Sung MK. Sexand gender-specific disparities in colorectal cancer risk. World J Gastroenterol 2015;21:5167-5175.

5. Brenner H, Kloor M, Pox CP. Colorectal cancer. Lancet 2014;383:1490-1502.

6. Iacopetta B. Are there two sides to colorectal cancer? Int J Cancer 2002;101:403-408.

7. Benedix F, Kube R, Meyer F, et al. Comparison of 17,641 patients with right- and left-sided colon cancer: differences in epidemiology, perioperative course, histology, and survival. Dis Colon Rectum 2010;53:57-64.

8. Kaku E, Oda Y, Murakami Y, et al. Proportion of flat- and depressed-type and laterally spreading tumor among advanced colorectal neoplasia. Clin Gastroenterol Hepatol 2011;9:503-508.

9. Parra-Blanco A, Ruiz A, Alvarez-Lobos M, et al. Achieving the best bowel preparation for colonoscopy. World J Gastroenterol 2014;20:17709-17726.

10. Rex DK, Schoenfeld PS, Cohen J, et al. Quality indicators for colonoscopy. Gastrointest Endosc 2015;81:31-53.

11. Serper M, Gawron AJ, Smith SG, et al. Patient factors that affect quality of colonoscopy preparation. Clin Gastroenterol Hepatol 2014;12:451-457.

12. Gandhi K, Tofani C, Sokach C, Patel D, Kastenberg D, Daskalakis C. Patient characteristics associated with quality of colonoscopy preparation: a systematic review and meta-analysis. Clin Gastroenterol Hepatol 2018;16:357369.

13. Ness RM, Manam R, Hoen H, Chalasani N. Predictors of inadequate bowel preparation for colonoscopy. Am J Gastroenterol 2001;96:1797-1802.

14. Saunders BP, Fukumoto M, Halligan S, et al. Why is colonoscopy more difficult in women? Gastrointest Endosc 1996;43:124-126.

15. Khashab MA, Pickhardt PJ, Kim DH, Rex DK. Colorectal anatomy in adults at computed tomography colonography: normal distribution and the effect of age, sex, and body mass index. Endoscopy 2009;41:674-678.

16. Yoo S, Lee KH, Lee HJ, et al. Seoul National University Bundang Hospital's electronic system for total care. Healthc Inform Res 2012;18:145-152.

17. Aronchick CA. Bowel preparation scale. Gastrointest Endosc 2004;60:1037-1038.

18. Rostom A, Jolicoeur E. Validation of a new scale for the assessment of bowel preparation quality. Gastrointest Endosc 2004;59:482-486.

19. Kastenberg D, Bertiger G, Brogadir S. Bowel preparation quality scales for colonoscopy. World J Gastroenterol 2018;24:2833-2843.

20. Parmar R, Martel M, Rostom A, Barkun AN. Validated scales for colon cleansing: a systematic review. Am J Gastroenterol 2016;111:197-204.

21. Calderwood AH, Jacobson BC. Comprehensive validation of the Boston Bowel Preparation Scale. Gastrointest Endosc 2010;72:686-692.

22. Clark BT, Protiva P, Nagar A, et al. Quantification of adequate bowel preparation for screening or surveillance colonoscopy in men. Gastroenterology 2016;150:396-405. 
23. Lai EJ, Calderwood AH, Doros G, Fix OK, Jacobson BC. The Boston bowel preparation scale: a valid and reliable instrument for colonoscopy-oriented research. Gastrointest Endosc 2009;69:620-625.

24. Kilminster S, Downes J, Gough B, Murdoch-Eaton D, Roberts T. Women in medicine: is there a problem? A literature review of the changing gender composition, structures and occupational cultures in medicine. Med Educ 2007;41:39-49.

25. Menon R, Watson SE, Thomas LN, et al. Diet complexity and estrogen receptor $\beta$ status affect the composition of the murine intestinal microbiota. Appl Environ Microbiol 2013;79:5763-5773.

26. Kim JJ, Kim N, Park JH, et al. Comparison of tight junction protein-related gene mRNA expression levels between male and female gastroesophageal reflux disease patients. Gut Liver 2018;12:411-419.

27. Kotake K, Asano M, Ozawa H, Kobayashi H, Sugihara K. Gender differences in colorectal cancer survival in Japan. Int J Clin Oncol 2016;21:194-203.

28. Zheng B, Zhu YJ, Wang HY, Chen L. Gender disparity in hepatocellular carcinoma (HCC): multiple underlying mechanisms. Sci China Life Sci 2017;60:575-584.

29. Kang Y, Son H. Gender differences in factors associated with colorectal cancer screening: a national cross-sectional study in Korea. Asia Pac J Public Health 2017;29:495-505.

30. Din NU, Ukoumunne OC, Rubin G, et al. Age and gender variations in cancer diagnostic intervals in 15 cancers: analysis of data from the UK clinical practice research datalink. PLoS One 2015;10:e0127717.

31. Rotondano G, Rispo A, Bottiglieri ME, et al. Quality of bowel cleansing in hospitalized patients undergoing colonoscopy: a multicenter prospective regional study. Dig Liver Dis 2015;47:669-674.

32. Akere A, Otegbayo JA. Complete colonoscopy: impact of patients' demographics and anthropometry on caecal in- tubation time. BMJ Open Gastroenterol 2016;3:e0ooo76.

33. Chung JI, Kim N, Um MS, et al. Learning curves for colonoscopy: a prospective evaluation of gastroenterology fellows at a single center. Gut Liver 2010;4:31-35.

34. Faigel DO, Cotton PB; World Organization of Digestive Endoscopy. The London OMED position statement for credentialing and quality assurance in digestive endoscopy. Endoscopy 2009;41:1069-1074.

35. Lee JW, Kim NY, Cha BH, et al. Comparison between conventional $4 \mathrm{~L}$ polyethylene glycol and combination of 2 L polyethylene glycol and sodium phosphate solution as colonoscopy preparation. Korean J Gastroenterol 2010;56:299-306.

36. Jo SY, Kim N, Lee JW, et al. Comparison among conventional $4 \mathrm{~L}$ polyethylene glycol, split method of $4 \mathrm{~L}$ polyethylene glycol and combination of $2 \mathrm{~L}$ polyethylene glycol and sodium phosphate solution for colonoscopy preparation. Korean J Gastroenterol 2012;59:414-422.

37. Ell C, Fischbach W, Bronisch HJ, et al. Randomized trial of low-volume PEG solution versus standard PEG + electrolytes for bowel cleansing before colonoscopy. Am J Gastroenterol 2008;103:883-893.

38. Kelly NM, Rodgers C, Patterson N, Jacob SG, Mainie I. A prospective audit of the efficacy, safety, and acceptability of low-volume polyethylene glycol (2 L) versus standard volume polyethylene glycol (4 L) versus magnesium citrate plus stimulant laxative as bowel preparation for colonoscopy. J Clin Gastroenterol 2012;46:595-601.

39. Valiante F, Pontone S, Hassan C, et al. A randomized controlled trial evaluating a new 2-L PEG solution plus ascorbic acid vs 4 -L PEG for bowel cleansing prior to colonoscopy. Dig Liver Dis 2012;44:224-227.

40. Corporaal S, Kleibeuker JH, Koornstra JJ. Low-volume PEG plus ascorbic acid versus high-volume PEG as bowel preparation for colonoscopy. Scand J Gastroenterol 2010;45:1380-1386. 